\title{
Role of Educational Institutions in Building a Peaceful Society
}

\author{
Asma Gul*1, Tayyaba Bashir ${ }^{2}$ \& Javed Mustafa ${ }^{3}$ \\ 1. Department of Education, International Islamic University, Islamabad, Pakistan. \\ 2. Department of English, University of Kotli, Azad Jammu \& Kashmir, Pakistan. \\ 3. Department of Education, Khushal Khan Khattak University, Karak, Pakistan.
}

\begin{abstract}
Educational institutions' role is not limited to technology's progression or improvement in their social and economic values but also is to teach the lesson of harmony, humbleness, tolerance, equality, and justice. Educational institutions are not merely building individuals to strengthen society and eradicate the negativities but also to build a peaceful society. Pakistan's educational system is a complex one that does not merely involve government and private schools; there are also many registered or unregistered madrassas. Lack of regulation of the curriculum and monitoring of the activities of madrasas is a matter of concern. Terrorism, too, is linked to such madrasas, which contradicts and nullifies educational institutions' purpose and aim of building a peaceful society. The study applied the functionalism theoretical assumptions and employed Qualitative Document Analysis (QDA) based on the previous studies review of literature on educational institutions' role in building peaceful societies to figure out the gap and develop new findings. The study suggests committing the national educational system, with it, the school and its teachers so that from their work, they contribute towards building peace in society.
\end{abstract}

Keywords: Technology's Progression, Peaceful Society, Eradicate Negativity, Madrassas, Curriculum, Construct of Society.

\section{Introduction}

It has been widely recognized that peace and co-existence are critical for the sustainable growth and development of current and future generations. Furthermore, the education system is considered to be a vital element in building peaceful societies. The idea is to educate young children and young people about social integration, inclusion, prevention of discrimination, and addressing differences and conflicts without a culture of violence (Tibbitts, 2020). Ghosh et al. (2017) argue that logically education alone will not end wars or the deep causes of other types of violent conflicts in the world. Nevertheless, it is a path within reach of all that, with an adequate orientation, would allow societies to achieve peace. In the reorientation of the human race, the young generation is a clear hope towards principles of co-existence and respect for life. Gross \& Davies (2015) pedagogue and researcher of the theme of peace in the schools, propose to reconstruct the organizational culture of education in order to allow young citizens to understand and interpret reality and realize a critical reading of the world that makes it possible an education towards commitment and action and in favour of social justice and equity. However, these new guidelines bring tension between the old and the new in education, which increases due to the new dimensions such as teaching for peace deal with allusive aspects 
of teaching and the development of attitudes, hopes, fears, beliefs, frustrations, and dreams.

Milton \& Barakat, (2016), posited that the educational system for peace is based on exploring conditions and values among young people, enabling the expression of their ideas without fear of the previous generation's negative criticism. In this sense, the new methodologies change the way of seeing the students, since now they are perceived as active subjects who have the same rights of expression as educators and are at the same level of communication. In this same line of research, the contributions of researchers in peace and education such as Novelli et al., (2015) are valuable who argued that current educators must have adequate interpersonal relationships with learners, based on affection and respect, since the direction of authority should not be vertical but horizontal.

Similarly, a positive approach of Education for Peace is to make known that human beings are not violent by nature, and that the roots of violence are related more to psychological and social variables than to genetic links. As a support for this approach, there appears the development of humanistic theories in education, which have the confidence that the individual can change future generations and is not condemned to perpetrate violence for biological reasons (Reardon $\&$ Snauwaert, 2015b). This study leaves an open window in the formation of subjects in favour of the culture of peace, a space used in socio-pedagogical sciences. Therefore, efforts must be made to create school curricula that affirm that all students have an innate capacity to grow, learn, and fully develop. One of the most important roles of this new formation is to help explore and create conditions through which such growth can flourish at the human level (Gallagher, 2016).

\subsection{The Concept of Peace}

This conception of peace is similar to the concept of harmony, is the form of interdependence and cooperation between people in scenarios of justice, and non-violence is defined. Other ways of conceiving the conflict as an opportunity are through a positive change in handling conflicts and building respectful relationships with the other, and recognizing the different forms of violence (individual, social and political) (Tomar \& Hemlatta, 2016). Furthermore, peace also relates to the individual and collective experiences of violence in the present and the future's fear. These statements make it possible to infer that political, ethical, and civic formation should focus on developing in children and adolescents their capacities and possibilities to be worthy by themselves, respectful and careful with other forms of human and non-human life, and deeply responsible for the construction of a more democratic, peaceful, fair and inclusive country. Also, there must be a transformation of social perceptions about peace and non-violent ways of resolving conflicts (Adonteng-Kissi et al., 2019).

The political, ethical, and civic formation for the construction of peace affects the modes of pedagogical intervention that teachers carry out in their classrooms and the different scenarios of educational institutions in such a way that the formative intentionality of building peace and co-existence permeate the pedagogical practices in order to be affected and transformed towards the concretion of more democratic, participatory, inclusive and highly cooperative scenarios in the construction of knowledge (Zelizer, 2015). This finding is related to the approach of Zembylas et al., (2016), specifically in the statement according to which every educator in the framework of peace must consider the philosophical principles on which the pedagogical practice exercises, which leads him to reflect on it from the impact that this can have in the transformation of culture. 
The consolidation of favourable attitudes to peace and co-existence is largely defined by developing political, ethical, and citizen capacities that human beings empower when faced with having to live with others belonging to their same political community of reference (Novelli et al., 2017). This idea is related to the proposal of (Ilesanmi, 2018), who proposes the building of citizen competencies to transform them towards peaceful co-existence. Understanding competencies that facilitate such as transformation allows articulating the academic and knowledge formation with comprehensive integral development. It should cover cultural and social elements to develop skills that solve changing contexts (Pugh et al., 2016). This transformative intention of society and culture through citizen competencies (which involve participation, peaceful co-existence, and pluralism) can be developed as the school is a legitimate social institution. However, achieving these purposes is the educational community's task in general; otherwise, it would be reduced to classroom work, and political education for peace is not exhausted in such scenarios. Social and community initiatives are also involved (Bajaj, 2015).

\subsection{Education and Peace}

Within the framework of morality, there is a considerable field for such exploration. Education for peace plays an important role in developing awareness in perspective and understanding the world through value systems and ideologies. Schools will need to take on this task with energy and determination, to devote more time to such explorations than ever before, as students struggle to make sense of a world characterized by threat and uncertainty (Skovdal \& Campbell, 2015). Following this view, it is important to propitiate the correct spaces and times for students to manage their internal conflicts and confront the ideas and concerns of their society to make them feel free to communicate what they think and feel. In this way, they can assume the main actors' role in humanity's future (Reardon \& Snauwaert, 2015b). These new guidelines in the training process directly take up aspects of the theory of education for peace, in terms of its essentially holistic approach, raised by the researcher in education for peace such as (Novelli et al., 2017), who clarifies that much attention should be paid both to the development of learners' feelings and their cognitive abilities; therefore the expression of feelings in the classroom begins to play an important role in teachers and students. Fortunately, many teachers want to reflect on their humanitarian activities in the classroom to improve learning processes with their students. When these people manage to carry out self-training projects on socio-affective issues in their institutions, it increases their interest in providing spaces for students to freely express their emotions.

Nevertheless, for decades, Pakistan has been facing the biggest challenge of terrorism and extremism, consequently affecting all walks of life, including educational institutions. Therefore, the need to investigate educational institutions' active part in promoting education for peace is the call for every academic professional. This study's primary motivation is to use educational institutions as a forum to investigate the causes and consequences of extremism, bring about positive change in societal thought and mindset, convincing global societies that violence is not an inherent ingredient of Pakistani society and that all contributing factors must be investigated. This study is aimed to conduct a comprehensive review of the literature. The focus of the review is to analyse the role of educational institutions in building a peaceful society. A significant amount of research indicates that educational institutions such as schools directly impact the development of children and the development of citizenship in children and young people. They can affect their perceptions of individual and collective identities. Furthermore, educational institutions also shape the perceptions of youth regarding social and 
ethical norms and principles. These impacts shape the behaviour and attitude of youth towards society. The review is based on the rationale that there is a need to analyse educational institutions' role in developing and shaping society's orientation towards peace and conflict. This study focuses on high-quality and latest literature to analyse educational institutions' role in developing a peaceful society. The study begins with a brief review of the literature, followed by a description of the review's methodological structure. The study then presents the results in the form of a narrative, followed by a brief set of conclusions.

\section{Research Methodology}

As mentioned earlier, this research is based on a literature review and is thus categorized as a qualitative inquiry. Within the context of a philosophical position, the researcher has decided to take an interpretivism epistemological position. This choice is based on the fact that the study aims to analyse educational institutions' role in building a peaceful society, which is a subjective phenomenon by nature, and thus interpretivism is more suitable for this study (Bryman, 2016). Within this context, the study has conducted a qualitative method. The qualitative method is more suitable for a subjective phenomenon as it enables the gathering and analysis of rich and detailed data for research purposes researcher (Rubin \& Babbie, 2016). Furthermore, inductive reasoning was chosen as a research approach in this study. The inductive approach requires the researcher to explore patterns and generalities and develop theoretical foundations. This study used an inductive approach because it allowed the researcher to generalize the review (Silverman, 2016) and provided information specifically within the research question.

Furthermore, this study is based on secondary data only. The secondary data has been chosen because it is more time-efficient and cost-effective as compared to primary data. Typical secondary data research sources included articles published in academic journals and reports published by the government, international bodies, news agencies, and educational institutions. However, secondary data-based research methods are vulnerable to publication bias, such as government publications' political bias and low methodological rigor of other actors (Taylor et al., 2015). To overcome these weaknesses, the study must only collect data from research articles published in high-quality and authentic academic journals. The articles are published after careful analyses and editions, and therefore methodological rigor of the articles is considered to be higher than other secondary data sources.

\section{Education and Peaceful Society}

The construction of peace is a formative purpose when educational institutions work for healthy co-existence and peaceful resolution. It is also a social and political conquest that involves various sectors, including economic, political, State, and education, while demanding a more detailed historical analysis of the conditions that create persistent conflicts and violence and hinder peaceful society, justice, and equity (Goren \& Yemini, 2017). The construction of peace has gained greater interest from various actors (State, civil society, the international community, armed forces), interested in finding a political resolution to the armed conflict (Ball, 2016). From this perspective, building peace requires confronting the accumulation of traumas and damages (individual as well as collective, direct and indirect) that manifest themselves in symptoms of indifference, skepticism, depression, distrust, fear, pain, anger, and hatred. Faced with the trauma, historical memory must be established, the fractured social structure and the everyday trusts restored, and promote restitution and individual and collective 
transformative reparations (Gadotti, 2008).

Achieving peacebuilding achievements is directly linked to civil society's political strengthening to organize and contribute to positioning peace as a national public priority and of interest to all citizens. This social goal is also achieved with all sectors' involvement, such as education, to develop attitudes, beliefs, values, and behaviours. Furthermore, religious actors must also identify the victims' pain and their assistance until the social fabric is repaired (Chandler, 2015). The business community also has a role in proposing strategies to assume the costs of peacebuilding, investing time and resources in strengthening institutions, in the organization of communities, improving local governance, supporting education programs, employment, and peaceful resolution of conflicts (Hon-Chan, 2017). At the same time, achieving peace is achieved by recognizing the cooperative work of both gender and ethnic movements, finally identifying local and regional peace initiatives' potential to promote political participation and the social and community organization required in the constitution (Kenworthy et al., 2016).

\subsection{Co-existence: Peace is not the Absence of Conflict}

According to the research reviewed, it is possible to identify three main streams regarding peacebuilding and education for peace. The first of them is co-existence. Co-existence refers to the need to understand that the construction of peace is not the absence of conflict (Fontana, 2016). On the contrary, it is assumed that conflict is inherent to the relationships between human beings and, therefore, is a fundamental element to rethink peace and the various ways in which human beings resolve it under non-violent strategies, such as the creation of educational environments of healthy co-existence and recognition of diversity and difference (Goren \& Yemini, 2017). To this end, the relationship between peacebuilding and historical memory is proposed through museums' proposal as educational scenarios for peace. Also, this pedagogical approach of co-existence and peace is a transcendental element to carefully study the social and cultural structures that mainly cause conflicts and, in this way, avoid any emergence (or re-emergence) of violence (Bajaj, 2015).

\subsection{The Notion of State and National Identity}

The second stream of research is focused on developing national identity and the concept of State. There is a direct relationship between the construction of peace and the strengthening of an idea of State. In light of this relationship, it is understood as an institution that must create and guarantee peace conditions (Bajaj, 2015). According to Davies, 2016, peace is a right and a duty of mandatory compliance in almost all constitutions. It is understood as a duty insofar as it involves all citizens from its most formal aspect, related to the State and its institutions, to the most emergent, related to the social and civil society demands, which over time it becomes increasingly urgent and implies that different sectors and citizens must create the conditions to guarantee a sense of sustainable peace.

The educational institutions must pursue the objective of developing a concept of State and national identity in their students. The purpose is to integrate the collective identity. With love and dedication to a national identity, young people can accept the ideas of co-existence. In other words, they tend to prioritize national identity over regional, ethnic, religious, and racial identity, among others (Kenworthy et al., 2016). Conflicts often emerge due to differences in social and ethical norms and principles. The social and ethical norms and principles are almost 
always based on religious, racial, ethnic, and regional backgrounds and identities. A national identity propagates the idea that people with different cultures and religions having different values and ethics can co-exist along with their conflicts and differences in an environment of peace and stability (Goren \& Yemini, 2016).

\subsection{Culture: Peace versus Violence}

The third stream of this research is focused on promoting a culture of peace while opposing the culture of violence. There is a significant relationship between the construction of peace and the transformation of a culture of violence towards the consolidation of a peace culture (Gadotti, 2008). Goren \& Yemini, 2017, states that education for peace has the difficult task of transforming the habits through which the absence of peace and violence and war are naturalized as political means of resolution of the conflictive situations. According to Fontana, 2016, opportunities to increase peace depend on people learning to recognize their relevant imagination of peace. From this notion, education for peace contributes to promoting values, attitudes, knowledge, skills, beliefs, attributes, and practices based on values of peace, nondiscrimination, and human dignity. In this sense, education for peace enables a peaceful behaviour and non-violent solutions to the conflicts in the social relations and in the violent and war contexts.

Therefore, education and the school have the challenge of building peace in violent scenarios. For such effects, an aspect that shines to the extent that it seeks to inquire about education for peace is the methodologies that promote dialogues, transmit knowledge, and provide peace spaces (Skovdal \& Campbell, 2015). According to Chandler, 2015, both conventional methods based on the transmission of content and alternative methods based on teaching to the student are necessary to promote the acquisition of knowledge and skills for the conflicts' peaceful solution. For its part, Reardon \& Snauwaert, (2015a) states that education for peace is concerned with integrated and holistic strategies guided by the concept of peace, through which seeks to promote different forms of constructive dialogue for peace and the transformation of conflicts, which means helping to train both in the group and individual skills. (Ball, 2016), conclude that education for peace and formal or normal education is different both in intentions and practice. An example of this evident tension is how the teacher is conceived: as a facilitator who enhances his students' autonomy and responsibility (case of education for peace) or as a controller who intends to discipline and order them (case of formal or normal education).

\section{Political Function of Schools}

Another important theme in research related to education and peacebuilding is the pedagogical methods. Skovdal \& Campbell, (2015), relativizes the idea according to which one pedagogical method is superior or inferior to another. The study establishes that the possible faults in the pedagogical methods are a consequence of the social context or "the enveloping social structure." In this sense, the analysis of pedagogical practice must consider the social nature of pedagogy and the various factors that go through social reality (Senehi, 2015). Bajaj, (2015), raises the need for contextualization depending on the type of conflict. Hence, it is emphasized that education for peace has been linked to the problems that arise from the political contexts (social conflicts, armed conflicts, wars), particularly to the countries. In this way, the themes that are related depend to a large extent on the degree of incidence that the values and ideologies that at such and such a time are promoted have, of who have been constituted as the social movements that have developed or promoted public agenda, and of the social representations 
and perceptions that shape the interactions between individuals.

As for the school's political function, their role is crossed by socio-political categories framed beyond the educational context. (Zembylas et al., 2016), affirms that not to run the risk of revictimizing and perpetrating structural exclusion towards women or towards those who have historically been marginalized, it is imperative to empower these populations and expose the exclusions and other social injustices they have been the subject. This purpose of peacebuilding is coherent with what (Pugh et al., 2016) states, which posits that political education should not only emphasize how students learn to identify the symptoms of social problems and their possible causes but also how to get involved in the development of proposals that overcome the effects of the exclusion of large sectors of the population.

Based on these statements, it could be inferred that one of the political functions of the educational institution is to generate cultural and social transformations favourable to the consolidation of peace practices and values, representations of equality and justice, inclusion, good living, and democracy. For this educational purpose, a possible strategy is for girls, boys, and young people to learn about the history of the country, accurately identify the implications that structural violence has brought on the living conditions of citizens and discuss social challenges, economic, cultural, and political of what it means to learn to live together in a nation that calls itself a social State of law (Gallagher, 2016).

This is how the school has a comprehensive work of the problems faced by its members and a transforming work of culture and society. Some experts have identified that education is a powerful tool for these transforming effects, and without which, the developments in the culture, science, and technology of a country could not occur (Milton \& Barakat, 2016). Novelli et al., 2017), on the other hand, from a psychological and philosophical point of view, establishes that the school contributes to developing the abilities of the students so that they learn to see the world from the perspective of the other and to understand the fundamentals that result in cooperation and reciprocity for the construction of peace. From this perspective, the school must reflect with special care on how social interactions are fostered and strengthened in the function of good living and human flourishing. Complementarily, it must create spaces to discuss and propose strategies conducive to establishing democratic and inclusive relations and formalizing deeply democratic procedures, based on criteria of justice, care, and recognition, and committed to promoting rights (Zelizer, 2015).

Given these mentions of the school's political function, the construction of peace and coexistence in educational institutions constitutes an educational intention not only possible and executable but also of a transcendental nature for a country (Hon-Chan, 2017). In this sense, the notion according to which the school, transformation of practices, discourses, and teaching methods to construct peace scenarios, contributes to the development of attitudes, values, is configured in the knowledge and political practices (Goren \& Yemini, 2017). As mentioned earlier, to strengthen democracy, the citizen-political exercise and the practices of concertation of conflicts, based on reflections and discussions about the moral correlations that underlie all political practice (Adonteng-Kissi et al. , 2019).

General exploration of empirical research within the school's political function framework presents a favourable panorama to provide different points of articulation of this article. However, at the same time, they allow us to find a theoretical locus of analysis from the reflection of the transformation of pedagogical practices (Bajaj, 2015). In the literature 
reviewed, it is possible to infer that the various school peacebuilding initiatives emphasize primarily aspects related to the configuration of political subjectivities and perceptions, the development of political capacities (attitudes, values, and knowledge), the understanding of conflict, and school aggression (Kenworthy et al., 2016). They propose a fundamental political commitment to guarantee to girls, boys, and adolescents the recognition and legitimacy in their words, in such a way that they are taken into account as a fundamental part of decision-making, the development of their own human potential the building a joint basic trust. Some strategies are articulated to the meaning of normative deliberation, discussing problems that affect the interaction between human beings and between them and the environment and the relationship between memory and peacebuilding.

From a disciplinary approach about co-existence and peace in school, it is investigated by the information about what should be known and done by children and adolescents, describing the factors, emotions, conditions, attitudes, and aggressive behaviours that form a violent school environment as justification for any pedagogical intervention (Gadotti, 2008). Another group of research focuses on pedagogical practices and initiatives that teachers raise to promote social inclusion and create alternative learning environments in which children and adolescents are diverse in their cognition, sexual orientation, and gender. They can receive a quality education in their ethnicity without being discriminated against (Reardon \& Snauwaert, 2015a).

Regarding the limitations in the consolidation of a political function to build peace, studies illustrate the restrictions of education as it does not address in a particular way the challenges related to the inclusion of girls, boys, and adolescents with disabilities, violated or with special educational needs or belonging to marginalized communities (Goren \& Yemini, 2017). Other research emphasizes characterizing school violence by identifying factors associated with aggression, such as school climate, aggressive attitudes, and related forms. However, many of the investigations are more descriptive than analytical of the categories of school aggression and violence (Skovdal \& Campbell, 2015). In a complementary manner, these investigations present a broad panorama in terms of participatory methodologies for the design of training proposals; perform multivariate analyses of understanding of aggression and violence within the school, and propose articulations of peacebuilding with pedagogical alternatives of the transformation of values, attitudes, and forms of negotiation of conflicts (Power, 2015).

The study indicates the various challenges facing construction for peace and education for peace. In particular, the research exposes the challenges that the school must face, from which a question arises as to how to restructure to confront the impacts of violence (Gross \& Davies, 2015), especially when mass culture gradually weakens its cultural monopoly. It ceases to be a regular order to become a professional bureaucracy (Ghosh et al. ,2017), and when teachers are expected to promote more democratic attitudes in hierarchical institutional structures.

\section{Conclusion}

Based on this research's findings, it is possible to deduce that any peacebuilding process is intrinsically related to a political subject's constitution and the strengthening of girls and young people's citizen exercise. This approach is coherent with the approaches of (Van Ommering, 2015), specifically when he states that peace studies have focused more on borders, more on the margins than in the very centre of the disciplines. At the same time, peace is conceived as a dialectical issue, in which participation (active, collective, and individual) is transcendental, which allows us to establish that it is possible to think about the links between the construction 
of peace and the public virtues for peace. With the ethical and moral formation of citizenship, elements are offered to rethink peace not only as a right and a duty but also as an ethical and moral demand that requires the creation of conditions for human beings in their different distinctions of what real can co-exist without having to devastate each other. This approach is related to peace, which means learning to live in the conflict constructively, not necessarily the absence of armed conflict or war. In short, peace is a social construction that increasingly demands all citizens' co-responsibility linked to a political community. It is a conquest to be achieved, which involves different actors, sectors, and institutions. It commits the national educational system and, with it, the school and its teachers, so that from their work, they contribute to the development of the country from an ethical, political, and integral, and sustainable human development perspective.

The construction of peace is an educational project of dignification and humanization of citizens, which aims to contribute to social justice, recognize diversity and plurality as children and young people are subjects of their development, valid interlocutors before the instances of power, and subjects of rights and duties. Additionally, the construction of peace is a political commitment that positions citizens as human beings who are constantly seeking to be worthy of themselves and as citizens who regulate their actions by reading rights. Hence, a peacebuilding proposal from the school must necessarily be related to the development of political, ethical, and citizen capacities and the creation of institutional conditions that favour the encounter with the other under conditions of recognition, dignity, and care. A school that works hard to avoid humiliation, counteract violence, and promote the denunciation of the violation of rights. This implies recognizing the other as a subject of care and compassion, a subject of rights and duties, and a contributor to collective social achievement.

The construction of peace is motivated ethically and morally towards the configuration of humanity's project and, therefore, is oriented to human flourishing. The varied faces of humanity are there to interpolate each other and mobilize non-violent forms of co-existence. Cultivating humanity, precisely, is related to these issues. We all know that we continually confront each other from a simple and superficial reading of our selfishness, but the challenge is not there. The greatest challenge is recognizing humanity's features that lead us to create conditions of living in plurality. This means making explicit the desire and preparing to build collegiate desires, common and deeply respectful of the particularity of each human being and how in the exercise of their freedom impels us to expand the comprehensive frameworks of regulation of interaction so that these in their application avoid humiliation, injustice, and inequality. This means learning to live in plurality. Generating learning from this ethical principle is the condition of all political life.

\section{References}

Adonteng-Kissi, O., Adonteng-Kissi, B., Kamal Jibril, M., \& Osei, S. K. (2019). Communal Conflict Versus Education: Experiences of Stakeholders in Ghana's Bawku Conflict. International Journal of Educational Development, 65, 68-79. https://doi.org/10.1016/j.ijedudev.2017.08.002

Bajaj, M. (2015). 'Pedagogies of Resistance' and Critical Peace Education Praxis. Journal of Peace Education, 12(2), 154-166. https://doi.org/10.1080/17400201.2014.991914

Ball, S. J. (2016). Education, Justice and Democracy: The Struggle Over Ignorance and Opportunity. In A. Montgomery \& I. Kehoe (Eds.), Reimagining the Purpose of 
Schools and Educational Organisations: Developing Critical Thinking, Agency, Beliefs in Schools and Educational Organisations (pp. 189-205). Springer International Publishing. https://doi.org/10.1007/978-3-319-24699-4_14

Bryman, A. (2016). Social Research Methods. Oxford University.

Chandler, D. C. (2015). Resilience and the 'Everyday': Beyond the Paradox of Liberal Peace'. Review of International Studies, 4l(1), 27-48. https://doi.org/10.1017/S0260210513000533

Davies, L. (2016). Security, Extremism and Education: Safeguarding or Surveillance? British $\begin{array}{llll}\text { Journal of } & \text { Educational }\end{array}$ https://doi.org/10.1080/00071005.2015.1107022

Fontana, G. (2016). Education Policy and Power-Sharing in Post-Conflict Societies: Lebanon, Northern Ireland, and Macedonia. Springer.

Gadotti, M. (2008). Education for Sustainability: A Critical Contribution to the Decade of Education for Sustainable Development. Green Theory \& Praxis: The Journal of Ecopedagogy, 4(1), 15-64. https://doi.org/doi: 10.3903/gtp.2008.1.2

Gallagher, T. (2016). Shared Education in Northern Ireland: School Collaboration in Divided Societies. Oxford Review of Education, 42(3), 362-375. https://doi.org/10.1080/03054985.2016.1184868

Ghosh, R., Chan, W. Y. A., Manuel, A., \& Dilimulati, M. (2017). Can Education Counter Violent Religious Extremism? Canadian Foreign Policy Journal, 23(2), 117-133. https://doi.org/10.1080/11926422.2016.1165713

Goren, H., \& Yemini, M. (2016). Global Citizenship Education in Context: Teacher Perceptions at an International School and a Local Israeli School. Compare: A Journal of Comparative and International Education, 46(5), 832-853. https://doi.org/10.1080/03057925.2015.1111752

Goren, H., \& Yemini, M. (2017). Global Citizenship Education Redefined - a Systematic Review of Empirical Studies on Global Citizenship Education. International Journal of Educational Research, 82, 170-183. https://doi.org/10.1016/j.ijer.2017.02.004

Gross, Z., \& Davies, L. (Eds.). (2015). The Contested Role of Education in Conflict and Fragility. Sense Publishers. https://doi.org/10.1007/978-94-6300-010-9

Hon-Chan, C. (2017). Education and Nation-Building in Plural Societies: The West Malaysian Experience. Development Studies Centre, The Australian National University. https://openresearchrepository.anu.edu.au/bitstream/1885/131361/1/DSC_monograph_06.pdf

Ilesanmi, A. (2018). Nigeria Certificate in Religious Education Curricula and the Search for Peaceful Coexistence Among Christians and Muslims. Bulletin of Ecumenical Theology, 30, 82-103.

Kenworthy, J. B., Voci, A., Ramiah, A. A., Tausch, N., Hughes, J., \& Hewstone, M. (2016). Building Trust in a Postconflict Society: An Integrative Model of Cross-Group Friendship and Intergroup Emotions. Journal of Conflict Resolution, 60(6), 10411070. https://doi.org/10.1177/0022002714564427

Milton, S., \& Barakat, S. (2016). Higher Education as the Catalyst of Recovery in ConflictAffected Societies. Globalisation, Societies and Education, 14(3), 403-421. https://doi.org/10.1080/14767724.2015.1127749

Novelli, M., Cardozo, M. L., and Smith, A. (2015). A Theoretical Framework for Analysing the Contribution of Education to Sustainable Peacebuilding: 4Rs in Conflict Affected Contexts. UNICEF, 24.

Novelli, M., Lopes Cardozo, M. T. A., \& Smith, A. (2017). The 4RS Framework: Analyzing 
Education's Contribution to Sustainable Peacebuilding with Social Justice in Conflict-Affected Contexts. https://archive.nyu.edu/handle/2451/39660

Power, C. (2015). The Power of Education: Education for all, Development, Globalisation and UNESCO

Colin

Power:

Springer. https://www.springer.com/in/book/9789812872203

Pugh, M., Cooper, N., \& Turner, M. (2016). Whose Peace? Critical Perspectives on the Political Economy of Peacebuilding. Springer.

Reardon, B. A., \& Snauwaert, D. T. (2015a). Betty a. Reardon: A Pioneer in Education for Peace and Human Rights. Springer.

Reardon, B. A., \& Snauwaert, D. T. (2015b). Reflective Pedagogy, Cosmopolitanism, and Critical Peace Education for Political Efficacy. In B. A. Reardon \& D. T. Snauwaert (Eds.), Betty A. Reardon: A Pioneer in Education for Peace and Human Rights (pp. 181-198). Springer. https://doi.org/10.1007/978-3-319-08967-6_13

Rubin, A., \& Babbie, E. R. (2016). Empowerment Series: Research Methods for Social Work. Cengage Learning.

Senehi, J. (2015). The Role of Constructive, Transcultural Storytelling in Ethnopolitical Conflict Transformation in Northern Ireland. In Regional and ethnic conflicts: Perspectives from the front lines (pp. 227-38).

Silverman, D. (2016). Qualitative Research. SAGE.

Skovdal, M., \& Campbell, C. (2015). Beyond Education: What Role Can Schools Play in the Support and Protection of Children in Extreme Settings? International Journal of Educational Development, https://doi.org/10.1016/j.ijedudev.2015.02.005

Taylor, S. J., Bogdan, R., \& DeVault, M. (2015). Introduction to Qualitative Research Methods: A Guidebook and Resource. John Wiley \& Sons.

Tibbitts, F. L. (2020). Deliberative Democratic Decision Making, Universal Values, and Cultural Pluralism: A Proposed Contribution to the Prevention of Violent Extremism Through Education. Prospects, 48(1), 79-94. https://doi.org/10.1007/s11125-019$\underline{09444-2}$

Tomar, A., \& Hemlatta, R. (2016). Education for Peace: Need of the Hour for All Disciplines. http://27.109.7.66:8080/xmlui/handle/123456789/365

Van-Ommering, E. (2015). Formal History Education in Lebanon: Crossroads of Past Conflicts and Prospects for Peace. International Journal of Educational Development, 41, 200207. https://doi.org/10.1016/j.ijedudev.2014.06.009

Zelizer, C. (2015). The Role of Conflict Resolution Graduate Education in Training the Next Generation of Practitioners and Scholars. Peace and Conflict: Journal of Peace Psychology, 21(4), 589-603. https://doi.org/10.1037/pac0000135

Zembylas, M., Charalambous, C., \& Charalambous, P. (2016). Peace Education in a ConflictAffected Society. Cambridge University. 